\title{
Das Projekt TARVISION der FMH ist vielversprechend gestartet!
}

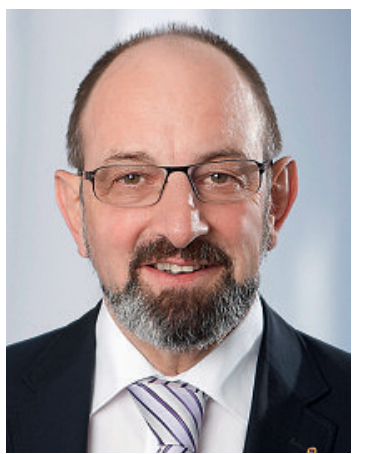

Dass im schweizerischen Gesundheitswesen Reformbedarf besteht, ist unbestritten. Doch je nach Sichtweise stehen sich die Ideen und Forderungen für die notwendigen Reformen diametral entgegen - was die Aufgabe nicht leichter macht. Bis heute gelang es nicht, eine gesamtschweizerische Gesundheitsstrategie zu entwickeln und nationale Gesundheitsziele festzulegen. Das hat natürlich auch mit unserem föderalistisch orientierten Gesundheitssystem zu tun. So war auch 2010 das Sparpaket des Bundes von unterschiedlichen Vorstössen und Ideen geprägt, die nicht ausgereift waren und schliesslich aus parteipolitischen Überlegungen Schiffbruch erlitten haben. Es stellt sich die Frage, ob das Parlament unter diesen Umständen überhaupt noch echte Gesundheitsreformen durchführen kann - oder ob nur noch Pflästerlipolitik möglich ist.

Doch gerade diese kurzfristigen Reformideen greifen viel zu wenig weit, im Vordergrund steht meist bloss der Spargedanke. Typisches Beispiel dafür ist die undifferenzierte Revision der Analysenliste. Das Bundesamt für Gesundheit (BAG) hatte 2009 für sämtliche Labortypen (Praxis-, Spitalund Privatlabor) Sparziele postuliert. Nun bestätigt das Monitoring des BAG die Befürchtungen der FMH: Nach der Revision lässt sich ein Praxislabor nicht mehr kostendeckend betreiben. Damit bringt das rein sektorielle Kostendenken ein wichtiges Instrument in der Grundversorgung und eine für die Behandlung der Patienten wichtige Dienstleistung zum Verschwinden. Es fehlt an Weitsicht für nachhaltige Reformen mit dem volkswirtschaftlichen Gesamtansatz, dass bessere Qualität letztlich Kosten spart.

\section{Es fehlt an Weitsicht für nachhaltige Reformen.}

Eine solche Reform ist das Tarifwerk TARMED, welches 2004 nach einer Zerreissprobe innerhalb der FMH zusammen mit den Partnern santésuisse, MTK und H+ umgesetzt wurde. Die vier Verbände haben sich zu TARMED Suisse zusammengeschlossen, welche den Tarif - im Sinne eines lernenden Systems - pflegt und neue Positionen ins Tarifwerk aufnimmt. Doch die betriebswirtschaftlichen Eckwerte von TARMED, etwa die Mieten oder die Gehälter des Perso- nals, basieren heute noch immer auf Daten aus den Jahren 1994 bis 1996. Leider ist es inzwischen nicht gelungen, das Tarifwerk anzupassen und weiterzuentwickeln. Verschiedene Revisionen sind am Widerstand der Versicherer gescheitert, welche der Kostenwahrheit nicht ins Auge schauen wollten: Während die Löhne der Beamten und Angestellten von Sozialversicherungen seit 1994 um 18\% gestiegen sind, sanken die Arzt- und Spitaltarife. Und um die Grundversorger besserzustellen, wird die Ärzteschaft immer wieder aufgefordert, eine Einkommensumverteilung innerhalb der FMH umzusetzen. Dies obwohl sich mit einer Umverteilung das unumstrittene Ziel niemals erreichen lässt. Die Eidgenössische Finanzkontrolle EFK und die Gesundheits-Direktoren-Konferenz GDK forderten vor kurzem sogar einen Eingriff in die Tarifautonomie durch den Bund. Offensichtlich habe beide nichts aus dem Prämienfiasko gelernt, als mehrere Krankenkassen mit erzwungenen Prämienreduktionen an den Rand des Konkurses getrieben wurden. Nun richtet sich der Fokus auf uns Leistungserbringer.

\section{Die FMH hat beschlossen, die Revision der Tarifstruktur TARMED selbst an die Hand zu nehmen.}

Deshalb macht die FMH nun ernst und hat im Sommer 2010 beschlossen, die Revision der Tarifstruktur TARMED mit dem Projekt «TARVISION» selbst an die Hand zu nehmen. Die Ärzteschaft beweist damit, dass sie sich aktiv für weitsichtige Lösungen einsetzt - so wie sie bei der Revision der Analysenliste das innovative «Point of care Modell» oder bei der ärztlichen Medikamentenabgabe ein neues Abgeltungsmodell entwickelt hat.

Das Projektkonzept «TARVISION» wurde Anfang September 2010 durch die Delegiertenversammlung der FMH genehmigt, der Kick-Off erfolgte am 20. Oktober 2010. Zu den wichtigsten Zielen gehören die Besserstellung der Grundversorger und die Anpassung der Kostenmodelle an die tatsächlichen Kosten. Die verschiedenen Fachgesellschaften arbeiten bereits mit viel Engagement daran, die Tarifstruktur an die aktuellen Gegebenheiten anzupassen, um am Schluss die reale Kostenwahrheit darzulegen. Wir erwarten, dass unsere Partner dann bereit sind, die Tarifrevision und die Tarifpflege gemeinsam mit uns weiterzuführen.

Dr. med. Ernst Gähler, Vizepräsident der FMH, Verantwortlicher Ressort Tarife und Verträge 